\title{
Using Improved Ant Colony Algorithm to Investigate EMU Circulation Scheduling Problem
}

\author{
Yu Zhou, ${ }^{1}$ Leishan Zhou, ${ }^{1}$ and Yun Wang ${ }^{2}$ \\ ${ }^{1}$ State Key Lab of Rail Traffic Control and Safety, Beijing Jiaotong University, Beijing 100044, China \\ ${ }^{2}$ MOE Key Laboratory for Urban Transportation Complex Systems Theory and Technology, Beijing Jiaotong University, \\ Beijing 100044, China
}

Correspondence should be addressed to Leishan Zhou; leishanzhou_bjtu@163.com

Received 22 April 2014; Accepted 16 June 2014; Published 7 July 2014

Academic Editor: Beatrice Paternoster

Copyright (c) 2014 Yu Zhou et al. This is an open access article distributed under the Creative Commons Attribution License, which permits unrestricted use, distribution, and reproduction in any medium, provided the original work is properly cited.

\begin{abstract}
High-speed railway is one of the most important ways to solve the long-standing travel difficulty problem in China. However, due to the high acquisition and maintenance cost, it is impossible for decision-making departments to purchase enough EMUs to satisfy the explosive travel demand. Therefore, there is an urgent need to study how to utilize EMU more efficiently and reduce costs in the case of completing a given task in train diagram. In this paper, an EMU circulation scheduling model is built based on train diagram constraints, maintenance constraints, and so forth; in the model solving process, an improved ACA algorithm has been designed. A case study is conducted to verify the feasibility of the model. Moreover, contrast tests have been carried out to compare the efficiency between the improved ACA and the traditional approaches. The results reveal that improved ACA method can solve the model with less time and the quality of each representative index is much better, which means that efficiency of the improved ACA method is higher and better scheduling scheme can be obtained.
\end{abstract}

\section{Introduction}

During the last two decades, China has seen dramatic increase in people movements which have grown up to 380 billion in 2013 [1]. With the eruptible increase, the problem of travel difficulty has become increasingly prominent in China. To solve this long-standing problem, great efforts have been paid to improve the transport capacity. One of the most impressive achievements is the huge development of high-speed railway (HSR) which is widely acknowledged to be of high capacity, high efficiency, and low energy [2]. Until 2014, China has the longest HSR network up to 11 thousand $\mathrm{km}$ in service with a rapid growth rate of $9.6 \%[1,3]$. Moreover, passenger volume of HSR has reached up to 54 million per month which is nearly double of air transport [4]. However, the rapid growth rate of HSR is far from sufficient in line with the explosive increasing demand of passenger transport. Although HSR development is a good way to mitigate the problem of insufficient transport capacity supply, due to the high acquisition cost of electric multiple unit (EMU) which is the main vehicle of HSR, it is impossible for the decision-making departments to purchase enough EMU so as to satisfy the explosive needs. Therefore, to improve the utilization efficiency of EMU is one of the most important means to alleviate the transportation difficulties problem.

EMU circulation scheduling is one of the key factors that influence the EMU utilization efficiency. Moreover, the difficulty of EMU circulation scheduling lies in the maintenance and train diagram constraints [5]. Extensive research has been carried out worldwide to explore the EMU circulation scheduling problem. In Europe, previous studies [6-10] have been largely focused on optimal allocation of EMU to carry out train trip task by coupling and uncoupling operations to meet the passengers' seat demand. A further study of railway rolling stock planning was carried out by Maróti [11] in which a model was built based on integer programming and solved with CPLEX. The focus of their study was the arrangements of coupling and uncoupling under the precondition of meeting passengers' demand. However, the situation in China is quite different from foreign countries. Because the $\mathrm{CRH}$ series trains are used as a whole, the operation problem of coupling and uncoupling is not considered. Therefore, in 
China, the main research priority is how to complete a given transport task with fewer EMUs and maintenance costs.

Previous research has found that the essence of EMU circulation scheduling problem is combinatorial optimization problem with a mass of constraints [12]. The results concluded that it was also a typical NP hard problem which could not be directly solved by ready-made software. Therefore, a thought of heuristic algorithm is proposed to solve the EMU circulation scheduling problem. Zhao et al. [13] explored different ways of utilizing EMU and they found that utilizing EMU with uncertain railroad region was an efficient way. Nie et al. [14] converted the EMU scheduling problem to assignment problem without considering the maintenance constraint and the Hungarian algorithm was used to solve the problem. Hong et al. [15] drew an integer programming model which took maintenance and train diagram constraints into consideration and a two-step strategy was put forward to solve this problem. Zhao and Tomii [16] use the local search and backtracking techniques to get a better result of this problem. Based on the previous studies, Keyu [17] designed a large neighborhood local search algorithm to find a better solution. Much research has been committed to improving the basic genetic algorithm and the efficiency has been further enhanced based on the improved algorithms [18-20]. Some scholars argued that EMU circulation scheduling problem could be seen as the tsp problem with constraints [21-23]. They provided a brand-new method for the solution and ant colony algorithm began to be used.

The majority of research on the solution of EMU circulation scheduling problem has applied modern intelligent optimization algorithms such as genetic algorithms, ant colony algorithm, and particle swarm optimization. The solving process in previous studies was always divided into two sections. However, they rarely considered the distance maintenance constraint in the first step of the solving process. This approach was of low efficiency and hard to be put into practice.

The motivation of this paper is to develop an EMU utilization model based on the analysis of EMU circulation scheduling problem. Furthermore, an improved ant colony algorithm is proposed in this paper based on the previous studies. What makes this study unique is that both the efficiency of solving process and the quality of solution have a huge breakthrough compared with previous studies.

The paper is organized as follows. Section 2 introduces the definition of EMU circulation scheduling problem. In Section 3, the EMU utilization model was developed. Section 4 included the design of improved ant colony algorithm and the solution process. Then, a case was given to verify the feasibility of the model as well as improved algorithm in Section 5. Finally, Section 6 provides concluding remarks.

\section{Statement of EMU Circulation Scheduling Problem}

The task in the train diagram undertaken by each train is called a trip. As is shown in Figure 1, only Station $C$ is near the Inspection and Repair Depot which is equipped

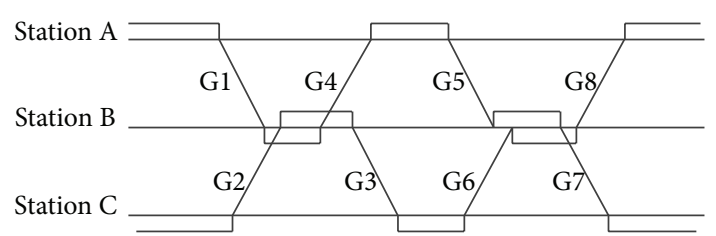

FIgURE 1: Train diagram.

with the maintenance facilities and G1 to G8 represent eight trips, respectively. The ordered sets of trips undertaken by the same EMU during the period of two adjacent maintenances are called one EMU circulation. Figure 2 shows the EMU circulation scheduling based on the train diagram. From this figure, it is clear that two EMUs are sufficient to complete the task in Figure 1. In the first day, after EMU1 undertakes the trips G1, G4, G5, and G7, it stays in the Station C and completes the maintenance while EMU2 starts from Station $\mathrm{C}$ and then completes the tasks of G2, G3, G6, and G8. In the next day, EMU1 repeats the track of EMU2 in the first day and then returns back to Station A while EMU2 repeats the track of EMU1 in the first day and then also completes the maintenance in Station C. When EMU1 and EMU2 return to their departure stations, respectively, a circulation has been completed. It should be noted that there may be a number of different EMU operation schemes based on the same train diagram.

The definition of EMU circulation scheduling problem in China can be described as using several EMU circulations to carry out all trips in the given train diagram under the condition of meeting train diagram and maintenance constraints. Figure 3 reveals three levels of this problem, namely, constraint layer, decision layer, and target layer.

(1) Constraint Layer. Constraint layer describes restrictions of EMU circulation scheduling problem including train diagram constraint, maintenance constraint, and other constraints.

(a) Train diagram constraint: the train diagram constraint requires that the circulation plan should contain all trips given in the train diagram. Furthermore, there are two kinds of technology time and the relationship between them should be satisfied. The first one is operation time which means the minimum preparation time for the next trip when the EMU completes a trip and arrives at the terminal station. The other one is dwell time which means the interval between two adjacent trips in the train diagram. As shown in Figure 4(a), the dwell time between two trips satisfies the operation time and the connection can be realized while Figure 4(b) cannot. Figure 4 reveals that only when dwell time is greater than the operation time can the connection be realized.

(b) Maintenance constraint: because of the high cost of EMU, the available EMUs are always scarce. Therefore, the utilization of available EMUs is extreme high 


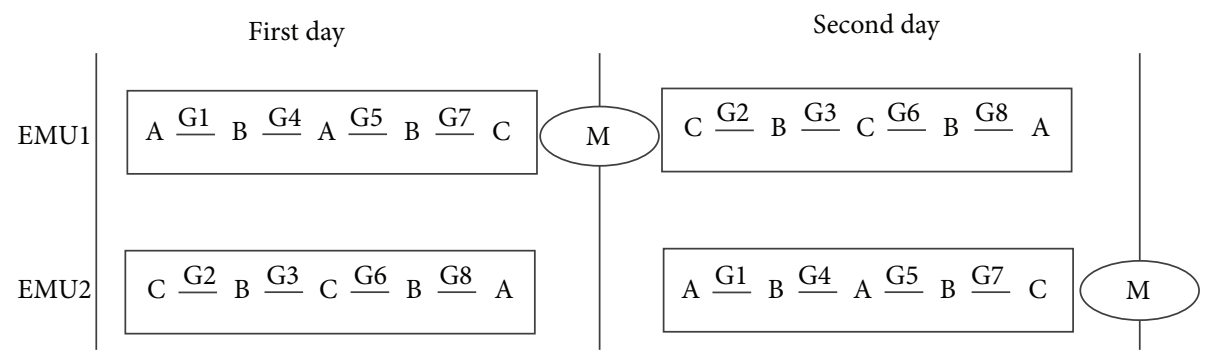

Figure 2: EMU circulation scheduling.

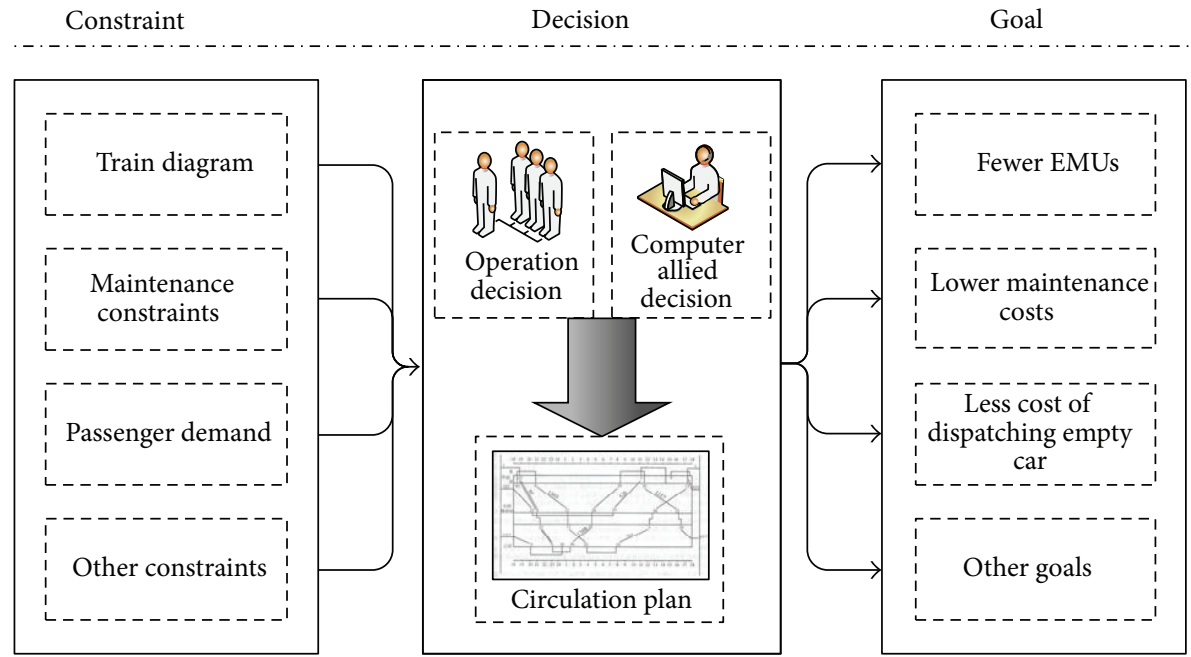

FIgURE 3: EMU circulation problem in China.

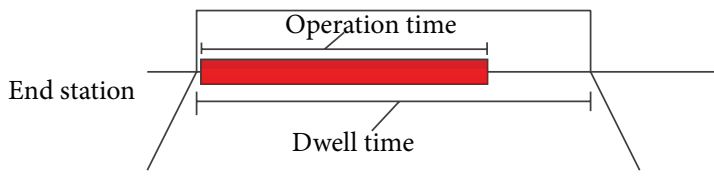

(a)

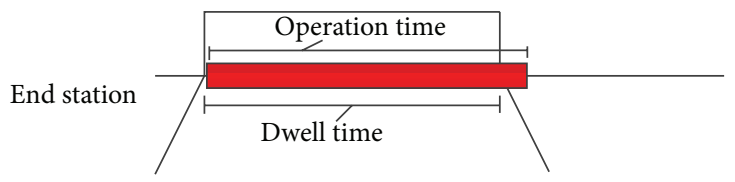

(b)

FIgURE 4: The dwell time constraint.

strength which may possibly cause passenger safety problem. So EMUs must be overhauled according to a certain level when the travel distance reaches a specified standard. What is more, in China, EMUs are allocated to fixed EMU depot which causes that, to accept overhaul, EMUs must return back to their EMU depot. There are two kinds of maintenance standards including operation distance and the travel time. Based on different requirements of operation distance or the travel time, EMU maintenance is divided into five levels [24]. Additionally, in practical applications, $10 \%$ fluctuation compared with the standards can be accepted (e.g., CRH1 should be overhauled with Level 1 maintenance in the travel distance range of $3600 \mathrm{~km}$ to $4400 \mathrm{~km}$ ). However, the maintenance periods of Level 2 to Level 5 are such long that generally they will not influence the compilation of the whole circulation plan. Therefore, in this study, only Level 1 maintenance is taken into consideration. Table 1 lists and defines the maintenance standards of different kinds of EMUs. And the maintenance time should not be less than 4 hours in order to guarantee the quality of maintenance.

(c) Other constraints: except for the train diagram and maintenance constraints, there are also some other constraints: (1) the transportation capability based on the EMU circulation plan should satisfy the passenger travel demand; (2) the type of the EMUs should meet the regulation of China Railway Corporation; 
TABLE 1: Level 1 maintenance standard of EMU in China.

\begin{tabular}{lcccc}
\hline Type & CRH1 & CRH2 & CRH3 & CRH5 \\
\hline Standard & $4 \times 10^{3} \mathrm{~km}$ or $48 \mathrm{~h}$ & $4 \times 10^{3} \mathrm{~km}$ or $48 \mathrm{~h}$ & $4 \times 10^{3} \mathrm{~km}$ or $48 \mathrm{~h}$ & $4 \times 10^{3} \mathrm{~km} \mathrm{or} 48 \mathrm{~h}$ \\
\hline
\end{tabular}

(3) to make the maintenance be carried out easier, the terminal station of circulation should be close to the Inspection and Repair Depot when the travel distance of EMU will soon reach the maintenance standard; (4) trains will occupy the arrival-departure track, storage siding, wheel repair line, or other fixed facilities when they are in the station or Inspection and Repair Depot. These factors also restrict the utilizing of the EMU.

(2) Goal Layer. The main objective is to improve the utilization of EMU which means complete the given task with as few EMUs as possible. Meanwhile, another goal is to reduce maintenance costs by controlling the maintenance frequency. There are also some other objectives such as reducing empty EMU dispatching and balancing the utilization of the EMU. Because EMU acquisition and maintenance cost accounts for the highest ratio of the whole cost, reducing the using amount of EMUs and reducing maintenance frequency are chosen as the two targets of this study.

(3) Decision Layer. The decision layer is the core content of this study. At the present stage, even though part of the computer aided decision has realized automation, most of the EMU circulation plans are still compiled by hand which will take a long time and energy even by experienced staff. Therefore, there is an urgent need to realize the automatic computer programming for the compilation of EMU circulation plan.

\section{Mathematics Model}

3.1. Model Assumption. To ensure the model feasible, the following basic assumptions are proposed.

Assumption 1. In China, most train diagrams of passenger dedicated line are drawn in pairs. Therefore, all train diagrams in this study are defined to be in pairs.

Assumption 2. In the process of continuation, it is presumed that there is only one type of EMU, because only the same types of EMU can connect with each other.

Assumption 3. In this paper, the EMUs are utilized with uncertain railroad region due to its advantages in efficiency [5].

Assumption 4. As mentioned before, maintenance standard includes operation distance and the travel time. However, due to the shortage of EMU resource, the everyday EMU operation mileage is such long that travel distance always reaches maintenance requirement before the travel time. Therefore, only the operation distance maintenance standard is taken into consideration in this study.
3.2. Model Building. The optimization model is based on a weighted directed graph $G(V, E, W)$, where $V$ denotes the set of all trips; $E$ denotes the set of connection, and $W$ represents the set of connecting weight. Elements in the sets $V, E$, and $W$ are defined as $v_{i}, e_{i j}$, and $w_{i j}$, respectively. The sets of $E$ and $W$ can be defined as follows:

$$
\begin{gathered}
E=\left\{e_{i j} \mid e_{i j}=\left(v_{i}, v_{j}\right)\right\}, \\
w_{i j}\left(v_{i}, v_{j}\right) \\
= \begin{cases}t_{j}^{d}-t_{i}^{a} & s_{j}^{d}=s_{i}^{a}, t_{j}^{d}-t_{i}^{a} \geq t_{i j} \\
1440+t_{j}^{d}-t_{i}^{a} & s_{j}^{d}=s_{i}^{a}, t_{j}^{d}-t_{i}^{a}<t_{i j} \\
+\infty & s_{j}^{d} \neq s_{i}^{a},\end{cases}
\end{gathered}
$$

where $v_{i}$ means trip $i$ which contains seven attributes including train number $n_{i}$, departure station $s_{i}^{d}$, arrival station $s_{i}^{a}$, departure time $t_{i}^{d}$, arrival time $s_{i}^{a}$, distance $s_{j}$, and running time $T_{i} ; e_{i j}$ denotes that trip $i$ is connected to trip $j ; w_{i j}$ is a weighted value to measure $e_{i j}$. There are three cases of $w_{i j}$ values: when the arrival station of trip $i$ is the same with the departure station of trip $j$ and the dwell time $t_{j}^{d}-t_{i}^{a}$ is bigger than the operation time $t_{i j}$, it means that trip $i$ can be connected with trip $j$ and $w_{i j}=t_{j}^{d}-t_{i}^{a}$ when $t_{j}^{d}-t_{i}^{a}$ is smaller than $t_{i j}$; the trip $j$ will wait until next day to connect trip $i$, so $w_{i j}=1440+t_{j}^{d}-t_{i}^{a}$; else, $w_{i j}$ is defined as infinity which means that trip $i$ cannot be connected to trip $j$.

In this study, the optimization objective includes two parts, fewer EMUs and lower maintenance costs. The amount of EMUs equals the value that 1440 divides the total time of all trips. Therefore, the goal of fewer EMUs can be converted to less total time of all trips which includes both running time and connecting time. Moreover, the running time $\sum_{1}^{n} T_{i}$ is unchanged which is given in the train diagram, so the goal of less total time is equivalent to make total connecting time smaller. No matter how long EMUs have travelled, once they are overhauled, the costs are the same. Therefore, due to the fixed cost of maintenance, the goal of lower maintenance costs means lowering the amount of maintenance.

Based on the above analysis, the model can be stated as follows.

Objective Function. Combinatorial optimization of the total connecting time and the amount of maintenance:

$$
\min \sigma_{1} \sum_{i=1}^{n} \sum_{j=1}^{n} x_{i j} w_{i j}+\sigma_{2} \sum_{i=1}^{n} \sum_{j=1}^{n} y_{i j}
$$

where $\sigma_{1}$ and $\sigma_{2}$ are weight coefficient of total connecting time and amount of maintenance, respectively; $x_{i j}$ and $y_{i j}$ are 
both bivariate. When trip $i$ is connected with trip $j$ by the same EMU, $x_{i j}$ is equal to one, otherwise zero. As shown in (4), the value of $y_{i j}$ is decided by $x_{i j}$ and $R_{i}$. Variable $R_{i}$ is also bivariate and when the arrival station of trip $i$ is near the Inspection and Repair Depot, the value of $R_{i}$ is one, otherwise zero. Only when $x_{i j}=1, R_{i}=1$, and maintenance standard has been reached, the value of $y_{i j}$ is one, otherwise zero:

$$
\begin{gathered}
x_{i j}, R_{i} \in\{0,1\} \\
y_{i j}= \begin{cases}1 & x_{i j}=1, \sum s_{i} \geq S_{\text {one }}, R_{i}=1 \\
0 & \text { others. }\end{cases}
\end{gathered}
$$

Restrictions. Constraint (5) restrains that the dwell time between trip $i$ and trip $j$ should be more than the operation time. In that case, EMU will be able to undertake next trip immediately after arriving at certain station:

$$
w_{i j} \geq t_{i j}
$$

Constraint (6) describes that the dwell time between trip $i$ and trip $j$ should be longer than the maintenance time when accumulated travel distance of an EMU reaches the maintenance standard:

$$
w_{i j} \geq T_{\text {one }} \text { when } \sum s_{i} \geq S_{\text {one }},
$$

where $T_{\text {one }}$ denotes the time of maintenance Level 1; $S_{\text {one }}$ denotes the distance standard of maintenance Level 1; $s$ in set $S=\{s \mid s=1, \ldots, m\}$ represents the station which contains arrival or departure trips.

Constraint (7) restricts that each trip could only be carried out once by one EMU and each EMU could only carry out one trip when it arrives at certain station:

$$
\begin{aligned}
& \sum_{i=1}^{n} x_{i j}=1 \\
& \sum_{j=1}^{n} x_{i j}=1 .
\end{aligned}
$$

Constraint (8) is the basic requirements:

$$
\begin{gathered}
i, j=1,2, \ldots, n, \quad i \neq j \\
\forall e_{i j} \in E \\
\forall v_{i}, v_{j} \in V .
\end{gathered}
$$

\section{Ant Colony Algorithm}

4.1. Traditional Ant Colony Algorithm. Ant colony algorithm (ACA) is an intelligence-optimized algorithm which is first proposed in 1992 [25]. ACA is an optimization method of distribution which advantages over three aspects [26]: firstly, ACA is a global optimization method which can be used for solving both the single objective and multiobjective optimization problems; secondly, ACA is appropriate for the discretization problems; thirdly, a positive feedback mechanism is used to obtain the optimal route through ceaselessly updating the pheromone. Therefore, due to the ability in finding optimal or near optimal solutions for many complex optimization problems, ant colony algorithm has been widely applied to various fields, such as the traveling salesman problem (TSP) [27-30], route optimization problem [31-34], traffic assignment problem $[35,36]$, crew scheduling problem [37-39], the network design problem [40], and many other classical combination optimization problems.

The inspiration of ACA comes from food-seeking behavior of ants [41]. By simulating the process of ants foraging in the nature, ACA tactfully combines biomimetic algorithm and heuristic algorithm. ACA takes full advantage of the ants' group ability that ants can find the shortest route from formicary to food by information transmission between individuals. Previous studies have found that group collaboration features of ants are communicated and coordinated by the pheromone which is a kind of volatile chemical left on the way back and forth [42]. When ants find a relatively short route, they will release the pheromone. Then, the higher the pheromone concentration is, the more attractive the route will be. Therefore, pheromone concentration on the shorter route will be even higher and all these processes form a positive-feedback loop. Eventually, ants on the multiple paths will gradually gather on the shortest route.

A lot of studies have stated that the ACA is quite applicable to solve TSP problem [27, 43]. EMU circulation scheduling problem is similar to TSP problem [21,44] which can be regarded as generalized TSP problem with some special constrains. Therefore, improved ACA is proposed to solve EMU circulation scheduling problem.

As previously mentioned, lots of research has used the ACA to figure out the EMU circulation scheduling problem. The solving process can be concluded roughly as is shown in Figure 5. In the first step, a whole circulation with short connection time can be obtained without distance maintenance constraint. Then, this circulation is divided into several segments with the consideration of maintenance constraint. In the second step, these segments are recombined and several new small circulations are obtained. However, artificial modification is usually needed as a supplement. This approach is low-efficient and the result is hard to be put into practice.

4.2. Improved Ant Colony Algorithm Design. To make solving process more efficient and results more accurate, an improved ACA is proposed and the solving process is shown in Figure 6. A group of ants are designed to construct a feasible solution. An unvisited node list is set to gather the unvisited trips and another list to record the path that the ant has traveled. In each process of iteration, one ant is generated to search for the path with the consideration of maintenance constraints and train diagram constraints. When the total travel distance reaches the maintenance standard, it should be judged whether the circulation meets the requirements that the departure station of first trip in this circulation should near the Inspection and Repair Depot and the terminal station 

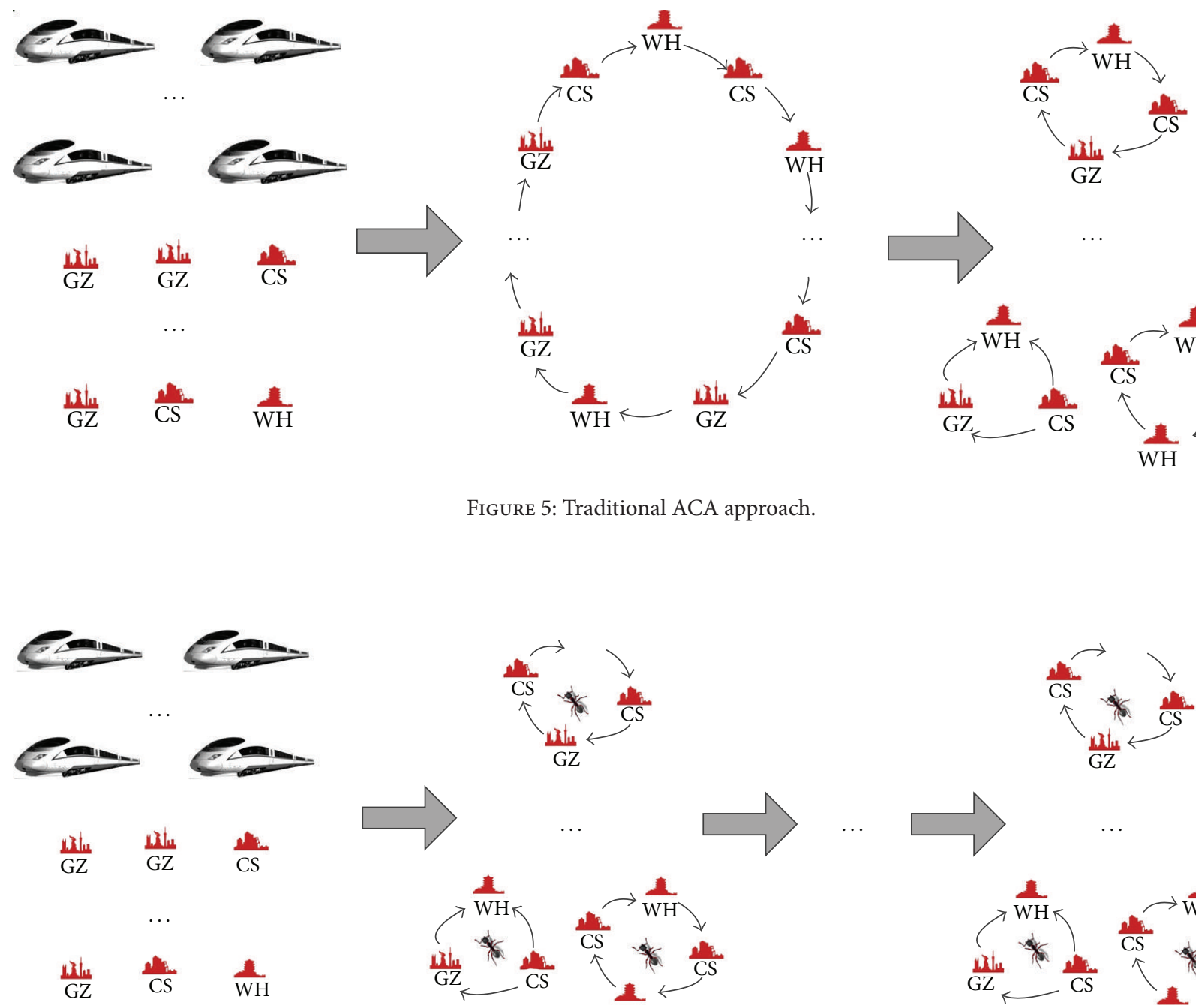

Figure 5: Traditional ACA approach.
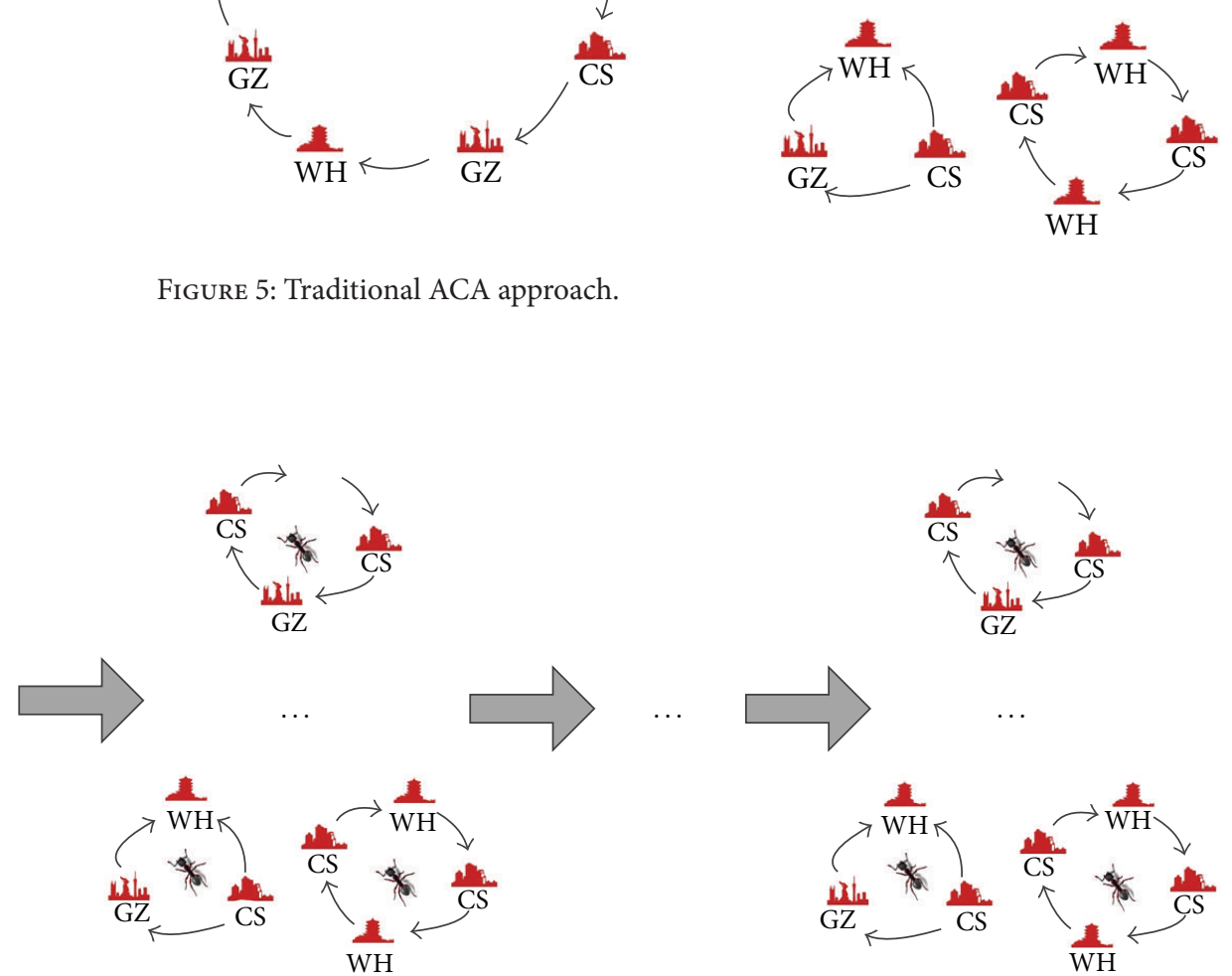

FIGURE 5. Traditional ACA approach.

Figure 6: Improved ACA approach.

of last trip should be the same with the departure station of first trip. If it meets the requirements, this circulation should be recorded and then another ant should be generated to repeat the process above and search for the next circulation; else, if the requirements cannot be satisfied, the backtracking technique should be used to search for another circulation which can meet the requirements. Once the circulation based on the backtracking technique is obtained, it should be recorded and another ant will be generated; otherwise, empty EMU should be dispatched to complete the circulation which should also be recorded and then another ant will be generated. Such new ant should be generated until the unvisited node list is empty which means that iteration has been completed. Relative information should be updated and then next iteration begins.

In each process of iteration, each ant is corresponding with a circulation loop and the quantity of the ant is uncertain which is different from the traditional ACA approach with a fixed ant quantity in each process of iteration. After all iterations, the result is obtained. The new approach proposed in this study leads to higher-quality solutions and faster solving speed.

Basic Mechanism and Rules. Path selection mechanism and pheromone update rule in our improved ACA are based on the classical ACA which can be described as follows.

Equation (9) describes the probability that ants transfer from node $i$ to node $j$ while nodes mean trips in this study:

$$
P_{i j}= \begin{cases}\frac{\operatorname{tau}(i, j)^{\alpha} \operatorname{eta}(i, j)^{\beta}}{\sum_{j=1, j \neq i}^{n} \operatorname{tau}(i, j)^{\alpha} \operatorname{eta}(i, j)^{\beta}} & s_{i}^{a}=s_{j}^{d} \\ 0 & \text { others }\end{cases}
$$

where $\operatorname{tau}(i, j)$ denotes the amount of pheromone deposited on the connection relationship $e_{i j}$ which can also be called track attraction and it is assumed that pheromone amount in every route is equal at the initial moment; eta $(i, j)$ represents vision attraction which equals the reciprocal of $w_{i j}$ when ants move from node $i$ to node $j ; \alpha$ and $\beta$ are the importance 
coefficient of track attraction and vision attraction, respectively.

Equations (10) and (11) describe the update rule of pheromone remained on the path by ants at the end of each iteration:

$$
\begin{gathered}
\operatorname{tau}(i, j)^{t+1}=(1-\operatorname{rho}) \times \operatorname{tau}(i, j)^{t}+\text { Delta_tau }(i, j) \\
\text { Delta_tau }(i, j)=\frac{Q}{\text { total_time }},
\end{gathered}
$$

where $t$ means the iteration index; rho describes the evaporation coefficient of pheromone; Delta_tau $(i, j)$ is the increasing amount of pheromone in the connection relationship. If there is no ant passing through the arc from trip $i$ to trip $j$, $\operatorname{Delta} \operatorname{tau}(i, j)$ is equal to zero; else, it is equal to the ratio of $Q$ and total_time, while total_time means the sum of all EMU connection time and $Q$ is defined as constant.

Preparation Work. To solve EMU circulation scheduling problem, some initial information and work should be prepared; namely,

(1) input basic data including train number, departure station, arrival station, distance, departure time, and arrival time,

(2) calculate the connection time according to (2),

(3) initialize the parameters including iteration times $N C$, current iteration index $t$, track attraction tau, vision attraction eta, $\alpha, \beta, Q$, and rho,

(4) group all the trips with the same departure station into set $V_{i}$, where $i$ denotes the number of the departure station,

(5) variable distance is defined to record the total travel distance of the ant while set path ${ }_{\mathrm{ant}}$ is defined to record the path that ants have traveled.

Solution Procedure. After the preparation work, the framework of improved ant colony algorithm for EMU circulation scheduling problem can be described as the flowchart in Figure 7.

(1) When $t<N C$, it means that iterative process does not end. Variables ant and distance are needed to be initialized with value zero. Moreover, set $V_{i}$ should be reset. Else, solution procedure ends and results will be outputted.

(2) If set $V_{i}(i=1,2, \ldots, n \not \subset \emptyset)$, ant $=$ ant +1 , a trip $v_{m}$ (assuming that the arrival station of $v_{m}$ is $j$ ) will be selected randomly from $V_{i}$. Then, update distance to the sum of distance and distance $v_{m}$. Trip $v_{m}$ needs

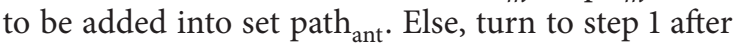
updating $\operatorname{tau}(i, j)$ according to (10).

(3) Search in set $V_{j}$ whose departure station is the same with the arrival station of trip $v_{m}$. Then, calculate the transfer probability according to (9) and use the roulette gamble to select next trip $v_{n}$ connecting with the last trip $v_{m}$, where updated distance is equal to the sum of distance and distance $v_{n}$. If no trip can meet requirements, empty EMUs need to be dispatched to finish the connection and then turn to step 2.

(4) If distance is smaller than the maintenance standard, delete $v_{n}$ from set $V_{j}$, add $v_{n}$ into set path ${ }_{\text {ant }}$, and then turn to step 3. Else, if the arrival station of last trip in set path ${ }_{\text {ant }}$ is the same with the departure station of first trip and the connecting time meets the maintenance demand, turn to step 2. Else, turn to step 5 .

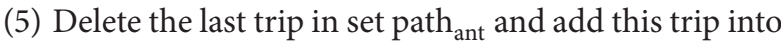
its original set $V_{j}$; update distance. Next, search for the next trip which can meet the train diagram and maintenance requirements from set $V_{k}$. Then, connect this trip with the last trip in the updated set path ${ }_{\text {ant }}$ and turn to step 2. If no such trip can be found, return all the trips in set path ant $_{\text {back into set }} V_{i}$ and then turn to step 2 .

After above steps, low-cost and high-efficient circulations can be produced.

\section{Numerical Analysis}

5.1. Basic Information. In this study, improved ant colony optimization algorithm is tested in a high-speed railway which includes 11 segments and 12 stations as is shown in Figure 8. CRH3 (CRHA380, speed $300 \mathrm{~km} / \mathrm{h}$ ) EMUs are chosen in passenger dedicated line to carry out experiments.

The basic information can be described as follows.

5.1.1. Departure and Arrival Stations. WH, CS, and GZ (WH and GZ are near the Inspection and Repair Depot).

5.1.2. Trips. There are total 154 trips including 52 trips from $\mathrm{WH}$ to GZ, 52 from GZ to WH, 25 from CS to GZ, and 25 from GZ to CS. The tested timetable data is listed in the supplementary file (see Supplementary Material available online at http://dx.doi.org/10.1155/2014/767429) which contains departure station, arrival station, departure time, arrival time, and train number.

5.1.3. Distance. The distance was $1068 \mathrm{~km}$ between WH and GZ and $801 \mathrm{~km}$ between CS and GZ.

5.1.4. Parameter. Consider $S_{\text {one }}\{d \mid 3600 \leq d \leq 4400\}$, $T_{\text {one }}=4 \mathrm{~h}$, total running distance $D_{\text {all }}=151,123 \mathrm{~km}$, and total running time $T_{\text {all }}=38,295$. The operation time $t_{i j}$ between a train arriving at certain station and undertaking next trip is $24 \mathrm{~min}$. The periodic time in train diagram is $T_{c}=1,440 \mathrm{~min}$. and the iteration times $N C$ are 50 .

According to previous study $[25,45]$, values of $\alpha, \beta, Q$, and rho are listed in Table 2.

5.2. Computational Results of EMU Circulation Scheduling Scheme. Due to the volatility of heuristic algorithm results, 


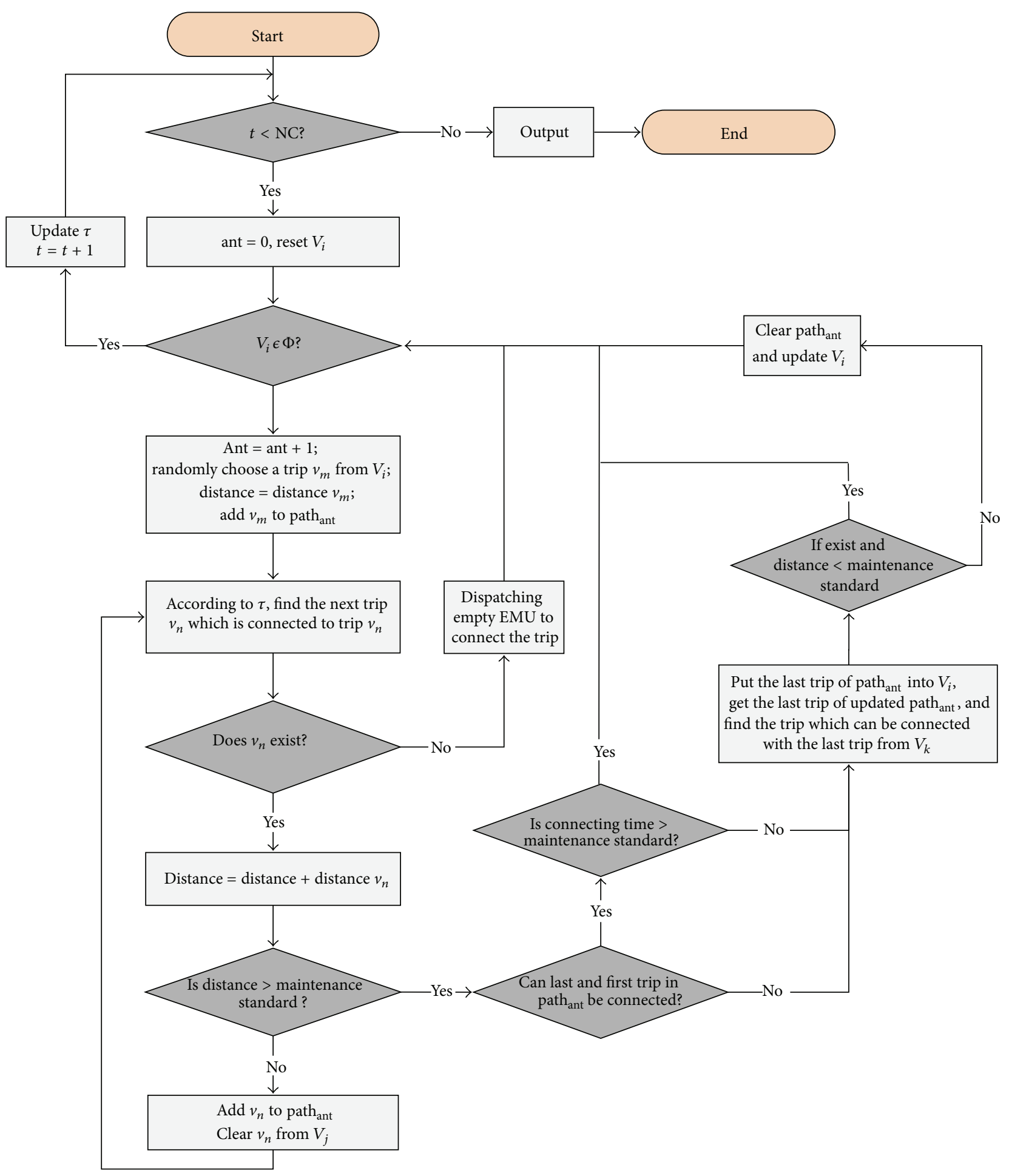

FIGURE 7: Solution procedure of improved ACA.

one hundred times of the improved ACA experiments have been carried out to ensure the stability of results. Software MATLAB programming is used in this study. After operating in the PC (Core i7, Frequency $3.40 \mathrm{GHz}$, Memory $16 \mathrm{G}$ ), results of EMU circulation scheduling scheme have been obtained. To make the experiment process more clear, six of the 100 convergence figures are chosen to express the iteration process.

As shown in Figure 9, the horizontal axis denotes iteration times and the vertical axis denotes the total connection time. The results reveal that the average convergence times of 100 experiments are 18.9 times while the average computational 


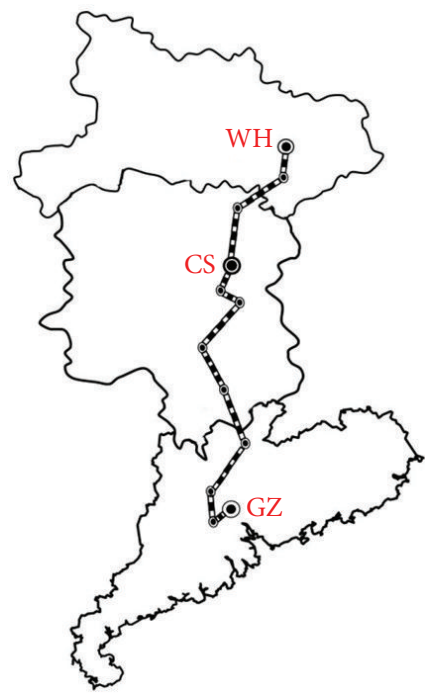

FIGURE 8: The tested high-speed railway.

TABLE 2: Values of coefficient.

\begin{tabular}{lccc}
\hline$\alpha$ & $\beta$ & $Q$ & rho \\
\hline 1 & 5 & 100 & 0.1
\end{tabular}

time is $2.53 \mathrm{~s}$. Of all the 100 experiments, the minimum total connection time $T_{\text {tct }}$ is $62,505 \mathrm{~min}$. The amount of utilizing EMUs $M_{\mathrm{EMU}}$ is 70 . Table 3 lists the EMU circulations and amount of EMUs completing each circulation where $M$ denotes maintenance.

The mean distance of every train per day $D_{\text {average }}$ is equal to $2158.9 \mathrm{~km}$ which is the value of $M_{\mathrm{EMU}}$ dividing $D_{\text {all }}$. The total amount of maintenance $N_{M}$ is 38 and the utilization rate of EMU $V_{k}$ is $37.991 \%$ which is equal to $T_{\text {all }} /(1440 * 70)$.

Results Evaluation. The minimum theoretical connecting time without considering the maintenance is $57,812 \mathrm{~min}$ which is calculated by the Hungarian algorithm [13]. In this study, the result based on the improved ACA method is $62,505 \mathrm{~min}$ which is very close to the theoretical result. In theory, the minimum total amount of maintenances is 35 which is equal to $D_{\text {all }} /(1+10 \%) S_{\text {one }}$. However, the ideal result cannot be reached in reality, because not all trains will be overhauled until they reach the maximum of distance maintenance standard. Therefore, the computational result, 38 times, in this study is satisfying. The mean distance of every train per day reaches $2158.9 \mathrm{~km}$ which means that the EMUs are utilized efficiently. These results have proved this algorithm feasible.

5.3. Comparison with Traditional Approach. In order to verify the high efficiency of this model and algorithm, two groups of comparative experiments are carried out by the genetic algorithm and traditional ant colony algorithm based on the same study case. Moreover, these experiments are carried out in the same computer. The comparison results are listed in Table 4.

According to Table 4, the EMU utilization rate $R$ of improved ACA $37.991 \%$ is much higher than that of traditional ACA 34.537\% and GA 32.431\% algorithm, which means that more efficient circulations have been scheduled by the improved ACA. To make the results more intuitional, several representative indexes are chosen to measure the efficiency of these three methods including $T_{\mathrm{tct}}, M_{\mathrm{EMU}}, N_{M}$, and $D_{\text {average }}$. The total connection time $T_{\text {tct }}$ of improved ACA is the smallest followed by traditional ACA and GA algorithm which means that the idle time of EMU circulation scheduling scheme obtained by improved ACA is much smaller and the arrangement is much better. Similarly, the amount of dispatched EMU $M_{\mathrm{EMU}}$ in the scheduling scheme obtained by improved ACA is smaller than the other two methods, which means that the efficiency of each EMU is much higher and the scheme is much better. Moreover, the maintenance times $N_{M}$ of improved ACA are less than the other two methods, which in other words means less cost. Inversely, the mean distance of every train per day $D_{\text {average }}$ is the longest by the method of improved ACA which means the higher efficiency of each EMU.

In summary, the method of improved ACA has been verified to be more efficient than the traditional algorithm for the EMU circulation scheduling problem and better results can be obtained. The results suggest that the same tasks can be completed with fewer EMUs and less cost at the same time.

\section{Conclusion}

In this study, an EMU circulation scheduling model is built based on train diagram constraints, maintenance constraints, and so forth and with optimization objective of reducing both the total connection time and the maintenance costs at 


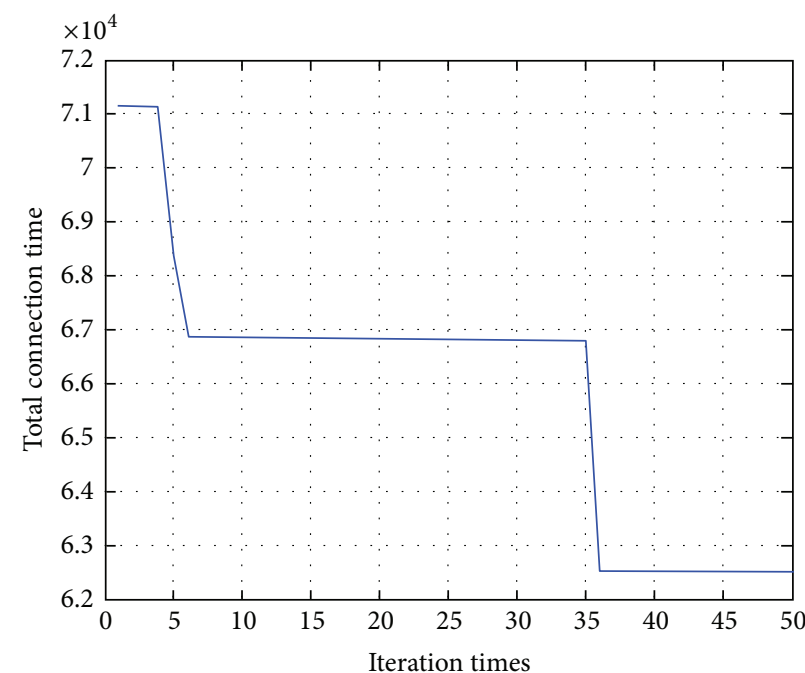

(a)

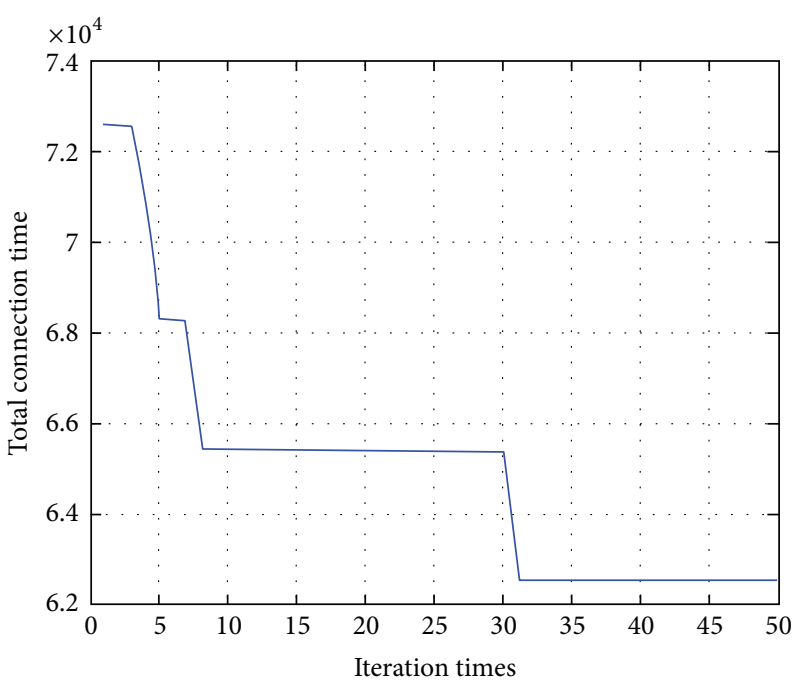

(c)

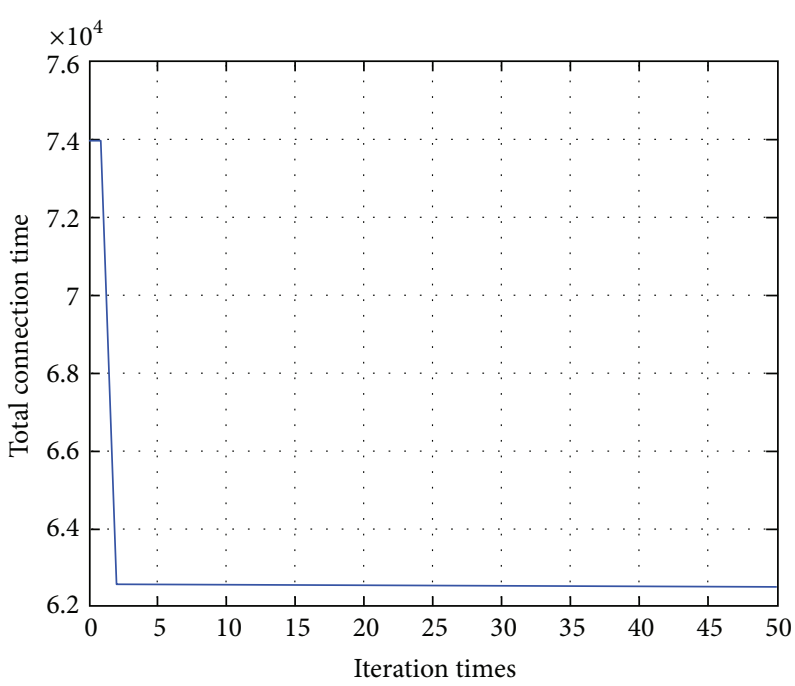

(e)

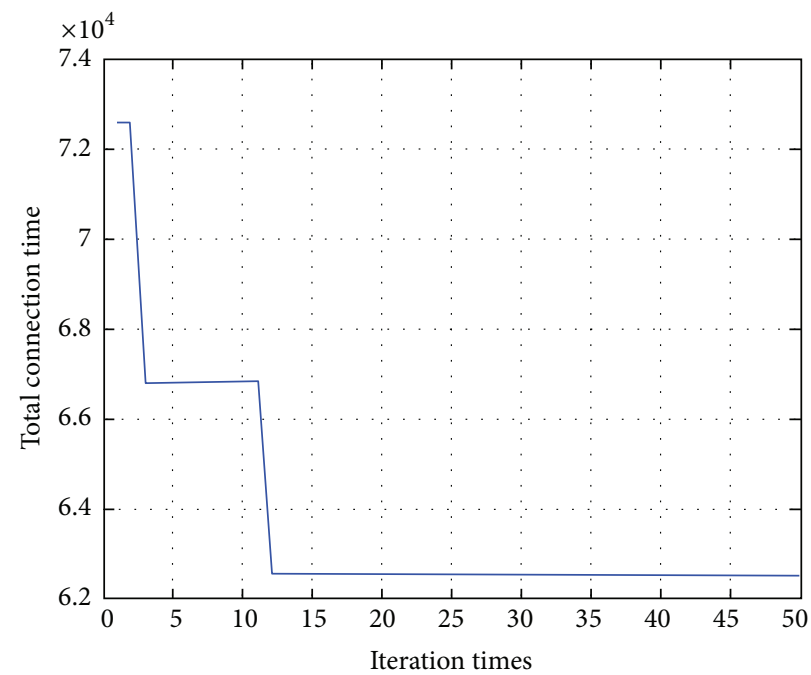

(b)

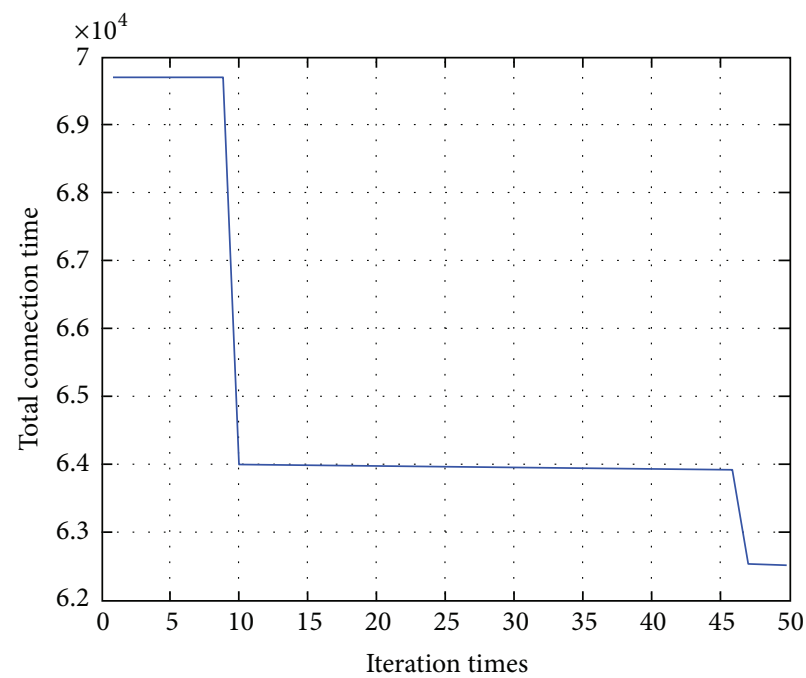

(d)

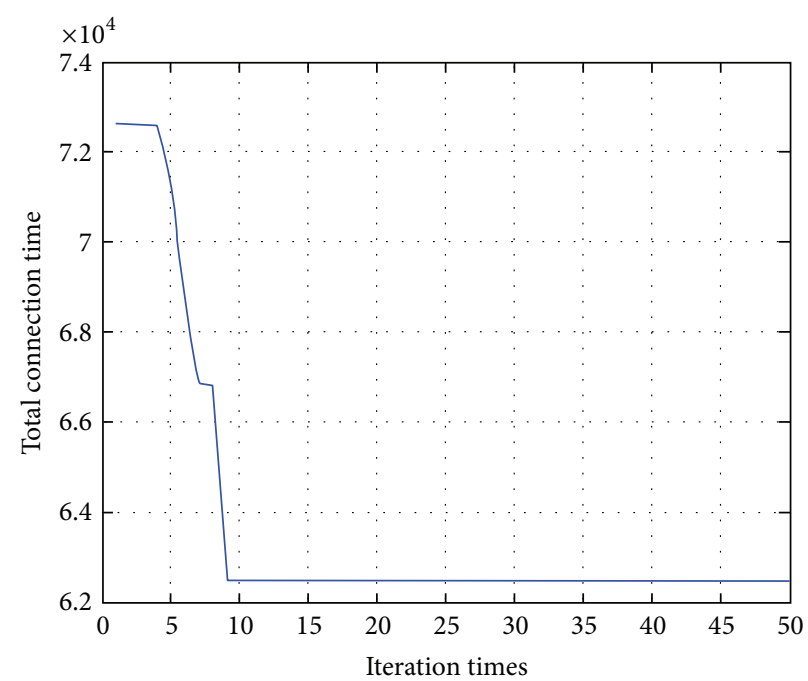

(f)

FIGURE 9: Iteration convergence process. 
TABLE 3: EMU circulation scheme result.

\begin{tabular}{|c|c|}
\hline EMU circulation & EMU amount \\
\hline $\mathrm{G} 1001 \rightarrow \mathrm{G} 6028 \rightarrow \mathrm{G} 6037 \rightarrow \mathrm{G} 1090 \rightarrow \mathbf{M} \rightarrow \mathrm{G} 1001$ & 1 \\
\hline $\mathrm{G} 1003 \rightarrow \mathrm{G} 1012 \rightarrow \mathrm{G} 1081 \rightarrow \mathrm{M} \rightarrow \mathrm{G} 1002 \rightarrow \mathrm{G} 1003$ & 2 \\
\hline $\mathrm{G} 1005 \rightarrow \mathrm{G} 6040 \rightarrow \mathrm{G} 6049 \rightarrow \mathrm{G} 1104 \rightarrow \mathrm{M} \rightarrow \mathrm{G} 1005$ & 1 \\
\hline $\mathrm{G} 1007 \rightarrow \mathrm{G} 6044 \rightarrow \mathrm{G} 6001 \rightarrow \mathrm{G} 1048 \rightarrow \mathbf{M} \rightarrow \mathrm{G} 1007$ & 2 \\
\hline $\mathrm{G} 1009 \rightarrow \mathrm{G} 6048 \rightarrow \mathrm{G} 6005 \rightarrow \mathrm{G} 1004 \rightarrow \mathbf{M} \rightarrow \mathrm{G} 1009$ & 2 \\
\hline $\mathrm{G} 1023 \rightarrow \mathrm{G} 6022 \rightarrow \mathrm{G} 6031 \rightarrow \mathrm{G} 1082 \rightarrow \mathbf{M} \rightarrow \mathrm{G} 1023$ & 1 \\
\hline $\mathrm{G} 1025 \rightarrow \mathrm{G} 6024 \rightarrow \mathrm{G} 6033 \rightarrow \mathrm{G} 1086 \rightarrow \mathbf{M} \rightarrow \mathrm{G} 1025$ & 1 \\
\hline $\mathrm{G} 1027 \rightarrow \mathrm{G} 6026 \rightarrow \mathrm{G} 6035 \rightarrow \mathrm{G} 1020 \rightarrow \mathbf{M} \rightarrow \mathrm{G} 1027$ & 1 \\
\hline $\mathrm{G} 1029 \rightarrow \mathrm{G} 1010 \rightarrow \mathrm{G} 1017 \rightarrow \mathrm{M} \rightarrow \mathrm{G} 1006 \rightarrow \mathrm{G} 1029$ & 2 \\
\hline $\mathrm{G} 1031 \rightarrow \mathrm{G} 1056 \rightarrow \mathrm{G} 1075 \rightarrow \mathrm{M} \rightarrow \mathrm{G} 1034 \rightarrow \mathrm{G} 1031$ & 2 \\
\hline $\mathrm{G} 1033 \rightarrow \mathrm{G} 6030 \rightarrow \mathrm{G} 6039 \rightarrow \mathrm{G} 1092 \rightarrow \mathbf{M} \rightarrow \mathrm{G} 1033$ & 1 \\
\hline $\mathrm{G} 1035 \rightarrow \mathrm{G} 1064 \rightarrow \mathrm{G} 1019 \rightarrow \mathrm{M} \rightarrow \mathrm{G} 1008 \rightarrow \mathrm{G} 1035$ & 2 \\
\hline $\mathrm{G} 1037 \rightarrow \mathrm{G} 1066 \rightarrow \mathrm{G} 1083 \rightarrow \mathrm{M} \rightarrow \mathrm{G} 1042 \rightarrow \mathrm{G} 1037$ & 2 \\
\hline $\mathrm{G} 1039 \rightarrow \mathrm{G} 6038 \rightarrow \mathrm{G} 6047 \rightarrow \mathrm{G} 1102 \rightarrow \mathrm{M} \rightarrow \mathrm{G} 1039$ & 1 \\
\hline $\mathrm{G} 1041 \rightarrow \mathrm{G} 1014 \rightarrow \mathrm{G} 1101 \rightarrow \mathrm{M} \rightarrow \mathrm{G} 1024 \rightarrow \mathrm{G} 1041$ & 2 \\
\hline $\mathrm{G} 1043 \rightarrow \mathrm{G} 1072 \rightarrow \mathrm{G} 1093 \rightarrow \mathrm{M} \rightarrow \mathrm{G} 1028 \rightarrow \mathrm{G} 1043$ & 2 \\
\hline $\mathrm{G} 1045 \rightarrow \mathrm{G} 6042 \rightarrow \mathrm{G} 6003 \rightarrow \mathrm{G} 1052 \rightarrow \mathrm{M} \rightarrow \mathrm{G} 1045$ & 2 \\
\hline $\mathrm{G} 1047 \rightarrow \mathrm{G} 1016 \rightarrow \mathrm{G} 1095 \rightarrow \mathrm{M} \rightarrow \mathrm{G} 1022 \rightarrow \mathrm{G} 1047$ & 1 \\
\hline $\mathrm{G} 1049 \rightarrow \mathrm{G} 1074 \rightarrow \mathrm{G} 1097 \rightarrow \mathrm{M} \rightarrow \mathrm{G} 1036 \rightarrow \mathrm{G} 1049$ & 2 \\
\hline $\mathrm{G} 1051 \rightarrow \mathrm{G} 6046 \rightarrow \mathrm{M} \rightarrow \mathrm{G} 6007 \rightarrow \mathrm{G} 1058 \rightarrow \mathrm{G} 1051$ & 2 \\
\hline $\mathrm{G} 1053 \rightarrow \mathrm{G} 1084 \rightarrow \mathrm{M} \rightarrow \mathrm{G} 1059 \rightarrow \mathrm{G} 1026 \rightarrow \mathrm{G} 1053$ & 2 \\
\hline $\mathrm{G} 1055 \rightarrow \mathrm{G} 1080 \rightarrow \mathrm{G} 1103 \rightarrow \mathrm{G} 1030 \rightarrow \mathrm{M} \rightarrow \mathrm{G} 1055$ & 1 \\
\hline $\mathrm{G} 1011 \rightarrow \mathrm{G} 1088 \rightarrow \mathrm{G} 1079 \rightarrow \mathrm{M} \rightarrow \mathrm{G} 1032 \rightarrow \mathrm{G} 1011$ & 2 \\
\hline $\mathrm{G} 1013 \rightarrow \mathrm{G} 1094 \rightarrow \mathrm{G} 1015 \rightarrow \mathrm{G} 1100 \rightarrow \mathrm{M} \rightarrow \mathrm{G} 1013$ & 2 \\
\hline $\mathrm{G} 1057 \rightarrow \mathrm{G} 6050 \rightarrow \mathbf{M} \rightarrow \mathrm{G} 6023 \rightarrow \mathrm{G} 1070 \rightarrow \mathrm{G} 1057$ & 2 \\
\hline $\mathrm{G} 1061 \rightarrow \mathrm{G} 1096 \rightarrow \mathrm{M} \rightarrow \mathrm{G} 1021 \rightarrow \mathrm{G} 1054 \rightarrow \mathrm{G} 1061$ & 2 \\
\hline $\mathrm{G} 1063 \rightarrow \mathrm{G} 1098 \rightarrow \mathrm{M} \rightarrow \mathrm{G} 1067 \rightarrow \mathrm{G} 1050 \rightarrow \mathrm{G} 1063$ & 3 \\
\hline $\mathrm{G} 1065 \rightarrow \mathrm{G} 6006 \rightarrow \mathrm{G} 6015 \rightarrow \mathrm{G} 1076 \rightarrow \mathrm{M} \rightarrow \mathrm{G} 1065$ & 2 \\
\hline $\mathrm{G} 1069 \rightarrow \mathrm{G} 6032 \rightarrow \mathrm{G} 6041 \rightarrow \mathrm{M} \rightarrow \mathrm{G} 1038 \rightarrow \mathrm{G} 1069$ & 2 \\
\hline $\mathrm{G} 1071 \rightarrow \mathrm{M} \rightarrow \mathrm{G} 6004 \rightarrow \mathrm{G} 6013 \rightarrow \mathrm{G} 1062 \rightarrow \mathrm{G} 1071$ & 2 \\
\hline $\mathrm{G} 1073 \rightarrow \mathrm{G} 6012 \rightarrow \mathrm{G} 6021 \rightarrow \mathrm{G} 1078 \rightarrow \mathrm{M} \rightarrow \mathrm{G} 1073$ & 2 \\
\hline $\mathrm{G} 1077 \rightarrow \mathrm{M} \rightarrow \mathrm{G} 1040 \rightarrow \mathrm{G} 1091 \rightarrow \mathrm{G} 1044 \rightarrow \mathrm{G} 1077$ & 2 \\
\hline $\mathrm{G} 1085 \rightarrow \mathrm{M} \rightarrow \mathrm{G} 6010 \rightarrow \mathrm{G} 6019 \rightarrow \mathrm{G} 1068 \rightarrow \mathrm{G} 1085$ & 2 \\
\hline $\mathrm{G} 1087 \rightarrow \mathrm{M} \rightarrow \mathrm{G} 6002 \rightarrow \mathrm{G} 6011 \rightarrow \mathrm{G} 1046 \rightarrow \mathrm{G} 1087$ & 2 \\
\hline $\mathrm{G} 1089 \rightarrow \mathbf{M} \rightarrow \mathrm{G} 6016 \rightarrow \mathrm{G} 6025 \rightarrow \mathrm{G} 1018 \rightarrow \mathrm{G} 1089$ & 2 \\
\hline $\mathrm{G} 1099 \rightarrow \mathbf{M} \rightarrow \mathrm{G} 6008 \rightarrow \mathrm{G} 6017 \rightarrow \mathrm{G} 1060 \rightarrow \mathrm{G} 1099$ & 2 \\
\hline $\mathrm{G} 6020 \rightarrow \mathrm{G} 6045 \rightarrow \mathbf{M} \rightarrow \mathrm{G} 6036 \rightarrow \mathrm{G} 6009 \rightarrow \mathrm{G} 6020$ & 3 \\
\hline $\begin{array}{l}\mathrm{G} 6018 \rightarrow \mathrm{G} 6027 \rightarrow \mathrm{G} 6014 \rightarrow \mathrm{G} 6029 \rightarrow \mathrm{G} 6034 \\
\rightarrow \mathrm{G} 6043 \rightarrow \mathbf{M} \rightarrow \mathrm{G} 6018\end{array}$ & 3 \\
\hline
\end{tabular}

the greatest extent. To solve this model, an improved ACA algorithm has been designed. A certain amount of ants are generated to search the circulations with the consideration of train diagram and maintenance constraints. The quantity of ants in each iteration process is uncertain which is different from traditional approaches. Moreover, to verify the feasibility of model, a case is conducted by MATLAB programming, and 100 times experiments have been carried
TABLE 4: Comparison of different approaches.

\begin{tabular}{lccc}
\hline & Improved ACA & Traditional ACA & GA \\
\hline$R$ & $37.991 \%$ & $34.537 \%$ & $32.431 \%$ \\
$T_{\text {tct }}(\min )$ & 62,505 & 68,521 & 72,358 \\
$M_{\mathrm{EMU}}$ & 70 & 77 & 82 \\
$N_{M}$ & 38 & 40 & 43 \\
$D_{\text {average }}(\mathrm{km} /$ day $)$ & 2158.9 & 1962.6 & 1842.9 \\
\hline
\end{tabular}

out according to the data of tested high speed railway. The results prove that the model and algorithm are feasible.

Additionally, contrast tests of traditional GA and ACA approaches have been carried out to compare the efficiency between the improved ACA and traditional approaches. The comparison results show that improved ACA method can solve the model with less time and the quality of each representative index is much better, which means that efficiency of the improved ACA method is higher than traditional approaches and better circulation scheduling scheme has been obtained.

On summary, the improved ACA method is much more efficient and accurate than traditional approaches. There may be some help of this paper in the EMU circulation scheduling problem while a given task in the train diagram can be completed with fewer EMUs and lower maintenance costs.

\section{Conflict of Interests}

The authors declare that there is no conflict of interests regarding the publication of this paper.

\section{Acknowledgment}

This work is financially supported by two Railway Ministry Science and Technology projects (Grants 2012X007-A, 2013X006-A).

\section{References}

[1] National Bureau of Statistics of China, 2013, http://www.stats .gov.cn/.

[2] H. Yang and A. Zhang, "Effects of high-speed rail and air transport competition on prices, profits and welfare," Transportation Research B: Methodological, vol. 46, no. 10, pp. 1322-1333, 2012.

[3] in Proceedings of the 2nd Conference of 12th National People's Congress, 2014.

[4] "High speed railway brings great changes in China," The New York Times, vol. 9, p. 25, 2013.

[5] Z. Peng, Y. Hao, and H. Anzhou, "Research on usage of HighSpeed passenger trains on uncertain railroad region," Journal of the China Railway Society, vol. 19, no. 2, pp. 15-19, 1997.

[6] A. Schrijver, "Minimum circulation of railway stock," CWI Quarterly, vol. 6, pp. 205-217, 1993.

[7] V. Cacchiani, A. Caprara, and P. Toth, "Solving a real-world train-unit assignment problem," Mathematical Programming, vol. 124, no. 1-2, pp. 207-231, 2010. 
[8] A. Arianna, R. Groot, L. Kroon, and A. Schrijver, "Efficient circulation of railway rolling stock," Transportation Science, vol. 40, no. 3, pp. 378-391, 2006.

[9] P. Fioole, L. Kroon, G. Maróti, and A. Schrijver, "A rolling stock circulation model for combining and splitting of passenger trains," European Journal of Operational Research, vol. 174, no. 2, pp. 1281-1297, 2006.

[10] E. Abbink, B. van den Berg, L. Kroon, and M. Salomon, "Allocation of railway rolling stock for passenger trains," Transportation Science, vol. 38, no. 1, pp. 33-41, 2004.

[11] G. Maróti, Operations Research Models for Railway Rolling Stock Planning, Technische Universiteit Eindhoven, Eindhoven, The Netherlands, 2006.

[12] P. Zhao and N. Tomii, "Train-set scheduling and an algorithm," Journal of the China Railway Society, vol. 25, no. 3, pp. 1-7, 2003.

[13] P. Zhao, H. Yang, and A. Hu, "Research on circulating optimization in the condition of using high-speed passenger trans in uncertain railroad region," Journal of Northern Jiaotong University, vol. 6, no. 21, pp. 621-624, 1997.

[14] L. Nie, P. Zhao, H. Yang, and A. Z. Hu, "Study on motor train-set operation in high speed railway," Journal of the China Railway Society, vol. 23, no. 3, pp. 1-7, 2001.

[15] S. Hong, K. M. Kim, K. Lee, and B. Hwan Park, "A pragmatic algorithm for the train-set routing: the case of Korea high-speed railway," Omega, vol. 37, no. 3, pp. 637-645, 2009.

[16] P. Zhao and N. Tomii, "An algorithm for train-set scheduling on weekday based on probabilistic local search," System Engineering: Theory \& Practice, vol. 2, no. 24, pp. 123-129, 2004.

[17] W. Keyu, Research on the EMU Assignment Problem under HighSpeed Rail Network, Beijing Jiaotong University, Beijing, China, 2012.

[18] J. Yang, H. Yang, and L. Haibo, "Application of genetic algorithm in optimizing EMU circulating model," Railway Transport and Economy, vol. 26, no. 7, pp. 65-68, 2004.

[19] C. Juanling, "Application of genetic algorithms to electric multiple unit scheduling," Journal of Transportation Engineering and Information, vol. 7, no. 2, pp. 67-71, 2009.

[20] X. Wenchao, Study on Oimization of Mtor Tain-set operation in High Speed Railway under Hybrid Operational Mode, Beijing Jiaotong University, Beijing, China, 2013.

[21] B. Wu, Optimizing Utilization of Electric Multiple-Unit on Passenger Dedicated Lines, Southwest Jiaotong University, Chengdu, China, 2012.

[22] X. Wang, Study on Passenger Delicated Lines Train-Set Scheduling, Lanzhou Jiaotong University, Lanzhou, China, 2007.

[23] L. Tong, L. Nie, and P. Zhao, "Application of ant colony algorithm in train-set scheduling problem," Journal of Transportation Systems Engineering and Information Technology, vol. 9, no. 6, pp. 161-167, 2009.

[24] Ministry of Railways of the People's Republic of China, Railway EMU Repair Procedures, Chinese Railway Press, Beijing, China, 2007.

[25] M. Dorjgo, Ant Colony Optimization, Politecnico Di Milano, Milan, Italy, 1992.

[26] K. Lei, X. Zhu, J. Hou, and W. Huang, "Decision of multimodal transportation scheme based on swarm intelligence," Mathematical Problems in Engineering, vol. 2014, Article ID 932832, 10 pages, 2014.
[27] M. Dorigo and L. M. Gambardella, "Ant colony system: a cooperative learning approach to the traveling salesman problem," IEEE Transactions on Evolutionary Computation, vol. 1, no. 1, pp. 53-66, 1997.

[28] A. Puris, R. Bello, and F. Herrera, "Analysis of the efficacy of a Two-Stage methodology for ant colony optimization: case of study with TSP and QAP," Expert Systems with Applications, vol. 37, no. 7, pp. 5443-5453, 2010.

[29] A. Uğur and D. Aydin, "An interactive simulation and analysis software for solving TSP using Ant Colony Optimization algorithms," Advances in Engineering Software, vol. 40, no. 5, pp. 341-349, 2009.

[30] J. Yang, X. Shi, M. Marchese, and Y. Liang, "An ant colony optimization method for generalized TSP problem," Progress in Natural Science, vol. 18, no. 11, pp. 1417-1422, 2008.

[31] L. Santos, J. Coutinho-Rodrigues, and J. R. Current, "An improved ant colony optimization based algorithm for the capacitated arc routing problem," Transportation Research B: Methodological, vol. 44, no. 2, pp. 246-266, 2010.

[32] H. Wang, G. Xiao, and Z. Wei, "Optimizing route for hazardous materials logistics based on hybrid ant colony algorithm," Discrete Dynamics in Nature and Society, vol. 2013, Article ID 752830, 6 pages, 2013.

[33] J. Ma and G. Sun, "Mutation ant colony algorithm of milkrun vehicle routing problem with fastest completion time based on dynamic optimization," Discrete Dynamics in Nature and Society, vol. 2013, Article ID 418436, 6 pages, 2013.

[34] Y. Zhou, Y. Dong, H. Xia, and J. Gu, "Routing optimization of intelligent vehicle in automated warehouse," Discrete Dynamics in Nature and Society, vol. 2014, Article ID 789754, 14 pages, 2014.

[35] L. D’Acierno, M. Gallo, and B. Montella, "An ant colony optimisation algorithm for solving the asymmetric traffic assignment problem," European Journal of Operational Research, vol. 217, no. 2, pp. 459-469, 2012.

[36] L. D'Acierno, B. Montella, and F. de Lucia, "A stochastic traffic assignment algorithm based on ant colony optimization," in Proceedings of the 5th International Workshop Ant Colony Optimization and Swarm Intelligence (ANTS '06), pp. 25-36, 2006.

[37] W.-H. Wu, S.-R. Cheng, C.-C. Wu, and Y. Yin, "Ant colony algorithms for a two-agent scheduling with sum-of processing times-based learning and deteriorating considerations," Journal of Intelligent Manufacturing, vol. 23, no. 5, pp. 1985-1993, 2012.

[38] G. Deng and W. Lin, "Ant colony optimization-based algorithm for airline crew scheduling problem," Expert Systems with Applications, vol. 38, no. 5, pp. 5787-5793, 2011.

[39] Y. Shen, K. Peng, K. Chen, and J. Li, "Evolutionary crew scheduling with adaptive chromosomes," Transportation Research Part B: Methodological, vol. 56, pp. 174-185, 2013.

[40] A. S. Mohaymany and A. Gholami, "Multimodal feeder network design problem: ant colony optimization approach," Journal of Transportation Engineering, vol. 136, no. 4, pp. 323-331, 2010.

[41] E. Mazloumi, M. Mesbah, A. Ceder, S. Moridpour, and G. Currie, "Efficient transit schedule design of timing points: a comparison of Ant Colony and Genetic Algorithms," Transportation Research B: Methodological, vol. 46, no. 1, pp. 217-234, 2012. 
[42] R. Beckers, J. L. Deneubourg, and S. Goss, “Trails and U-turns in the selection of a path by the ant Lasius niger," Journal of Theoretical Biology, vol. 159, no. 4, pp. 397-415, 1992.

[43] M. Dorigo and L. M. Gambardella, "Ant colonies for the travelling salesman problem," BioSystems, vol. 43, no. 2, pp. 7381, 1997.

[44] H. Li, Theory and Method Studies on EMU Scheduling Problem for High Speed Railway, Beijing Jiaotong University, Beijing, China, 2013.

[45] M. Dorigo, E. Bonabeau, and G. Theraulaz, "Ant algorithms and stigmergy," Future Generation Computer Systems, vol. 16, no. 8, pp. 851-871, 2000. 


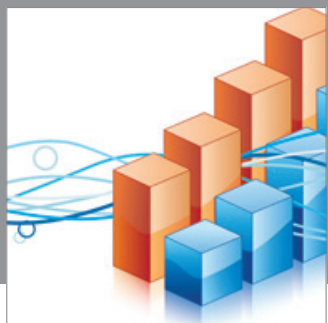

Advances in

Operations Research

mansans

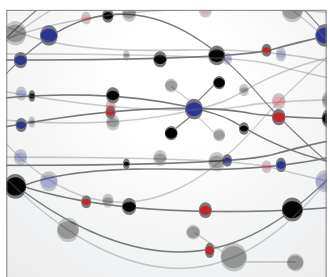

The Scientific World Journal
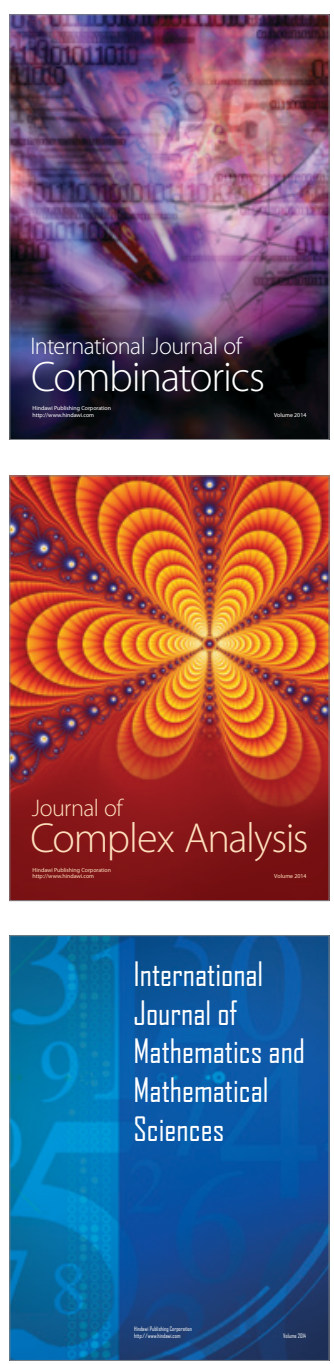
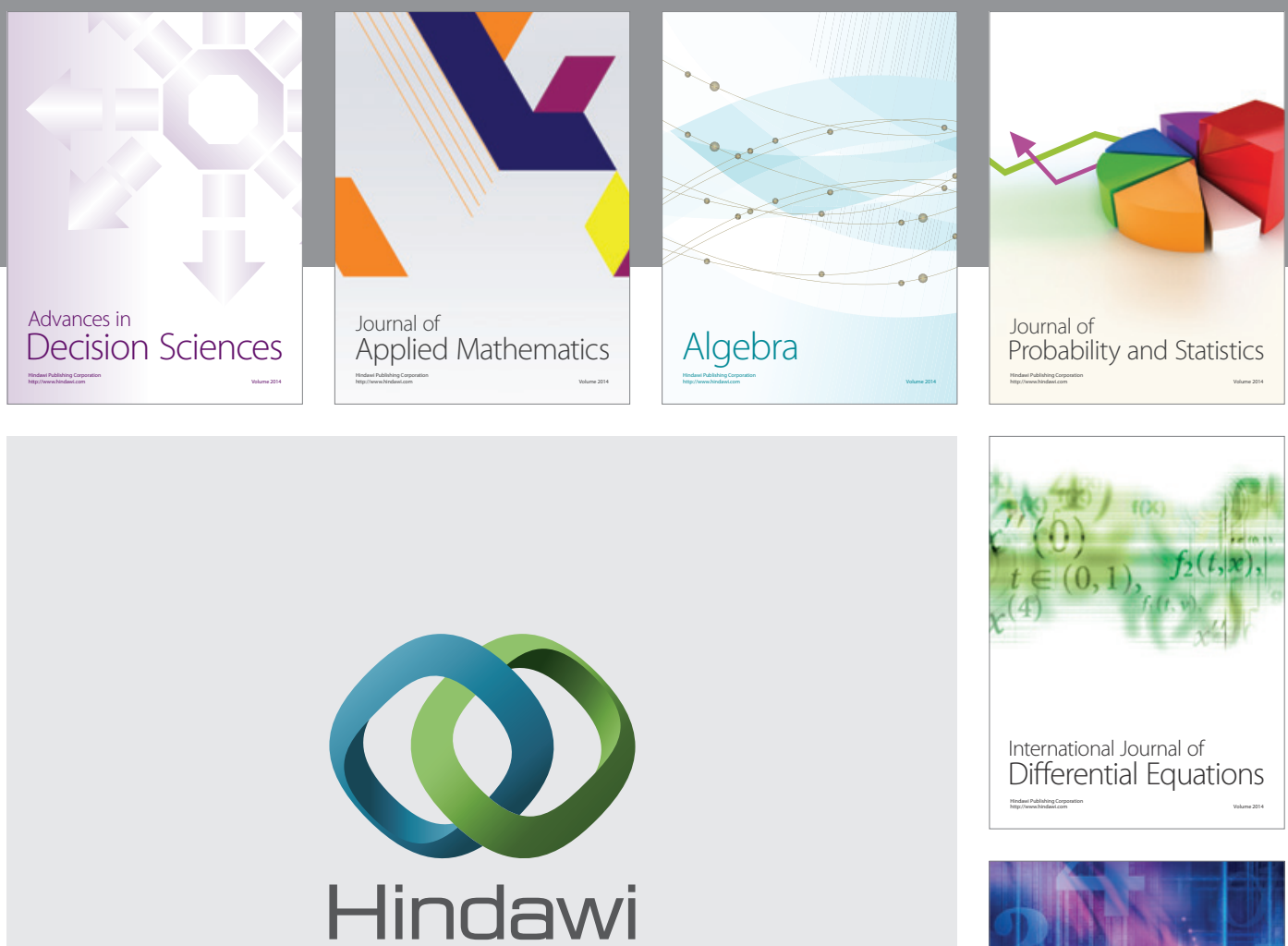

Submit your manuscripts at http://www.hindawi.com
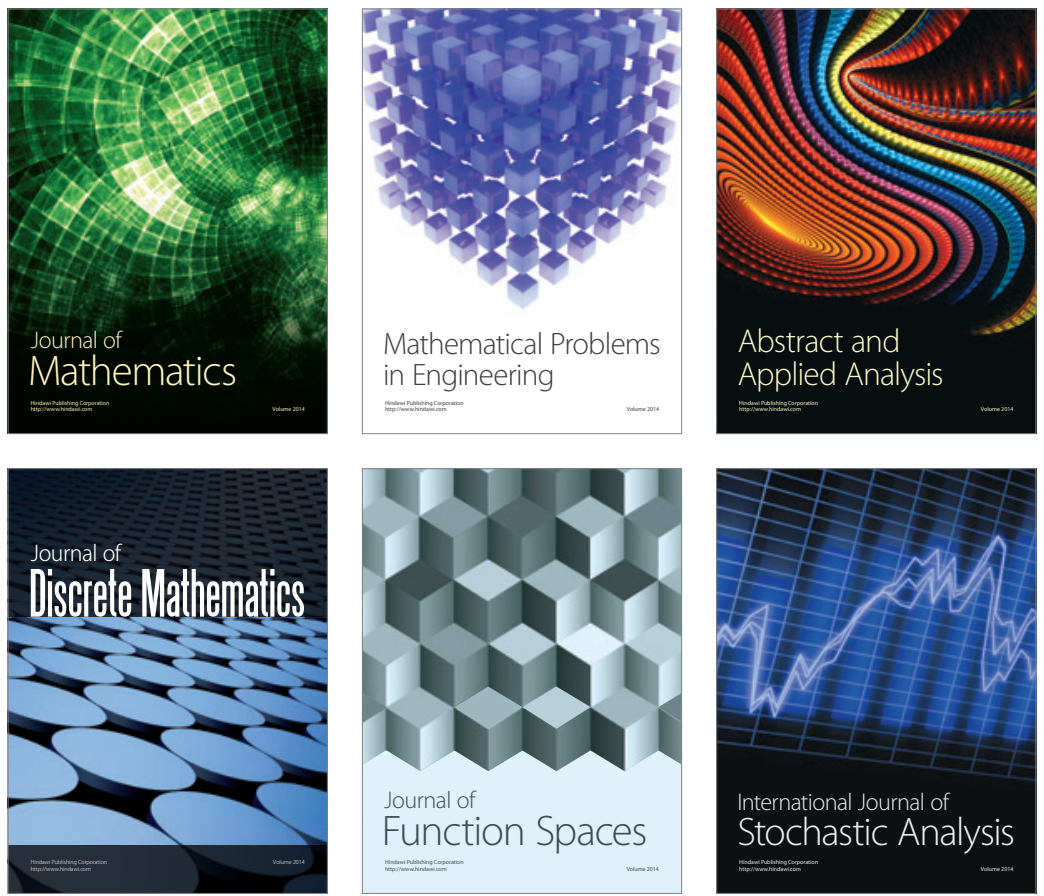

Journal of

Function Spaces

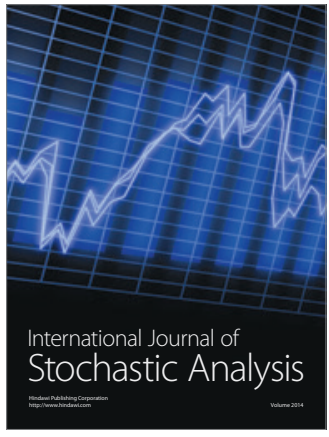

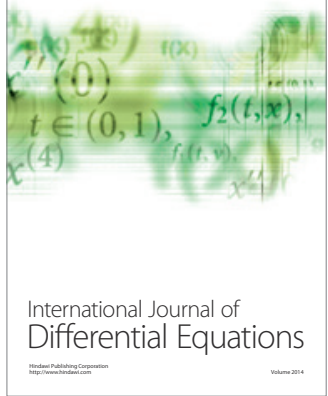
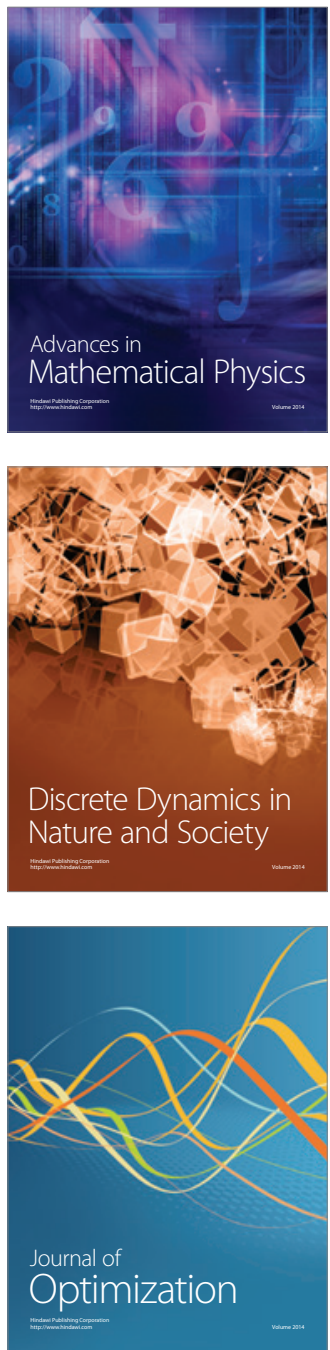